\title{
LIBROS Y LECTURA
}

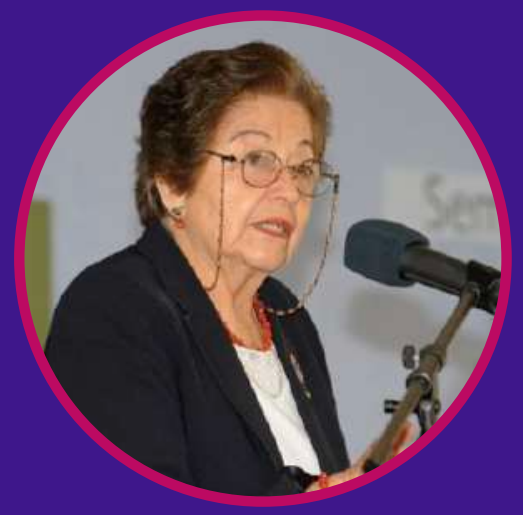

\section{La presencia del colofón en la historia del libro en México}

The presence of the colophon in the history of the book in Mexico

\author{
Dra. Rosa María Fernández de Zamora \\ Universidad Nacional Autónoma de México, México \\ rmfe@unam.mx
}

Recibido: 30 de julio de 2021.

Aceptado: 10 de septiembre de 2021.

Received: July 30th, 2021.

Publicado: 30 de noviembre de 2021.

Accepted: September 10th, 2021.

Published: November 30th, 2021.

\footnotetext{
(c) (i) $\odot$ Esta obra está bajo una licencia internacional Creative c) Commons Atribución-NoComercial-SinDerivadas 4.0.
}

DOI: https://doi.org/10.21555/rpc.vi2.2434

Cómo citar: Fernández de Zamora, R. M. . (2021). La presencia del colofón en la historia del libro en México. RPC, (2), 30-42. https://doi.org/10.21555/rpc.vi2.2434

Revista Panamericana de Comunicación, Año 3, N. 2, julio-septiembre 2021, pp. 30-42

\section{RESUMEN}

El colofón tiene una larga presencia en la historia del libro en México y, en el mundo, ha jugado un importante papel ya que ha proporcionado una información relevante para el conocimiento de las obras. Al llegar los incunables, el colofón poco a poco fue perdiendo importancia porque la portada daba la información necesaria, pero muchos incunables no tenían portada, entonces el colofón proporcionaba la información sobre el autor, el impresor, el lugar y la fecha de impresión y así continuó su presencia en los siglos siguientes hasta el presente. El artículo expone la evolución de las características del colofón en México basándose en una amplia selección de ilustraciones.

Palabras-clave: colofón, historia del libro, México

\section{ABSTRACT}

The colophon has a long presence in the history of the book in Mexico and, in the world, it has played an important role since it has provided relevant information for the knowledge of the works. When the incunabula arrived, the colophon gradually lost importance because the cover gave the necessary information, but many incunabula did not have a cover, so the colophon provided information about the author, the printer, the place and the date of printing and so on. its presence continued in the following centuries until today. The article presents the evolution of the characteristics of the colophon in Mexico based on a wide presentation of selected illustrations.

Keywords: colophon, history of the book, Mexico 
- I colofón tiene una larga presencia en la historia - del libro en México y, en el mundo, ha jugado un - importante papel ya que ha proporcionado una información relevante para el conocimiento de las obras.

Prácticamente todas las historias del libro mencionan en algún momento a esa pequeña parte del libro conocida como colofón. Los bibliógrafos europeos que se ocupan de los incunables dicen que esta última parte del libro fue herencia de los libros manuscritos y que si bien no todos los primeros impresos cuentan con él, muchos de ellos lo tienen y proporcionan información valiosa sobre el impreso en cuestión: el nombre del impresor, lugar y fecha de cuando se terminó la obra, el agradecimiento a Dios por haberla terminado.

Véase el colofón siguiente que aparece en la obra, De los incunables al siglo XVIII: Historia ilustrada del libro español

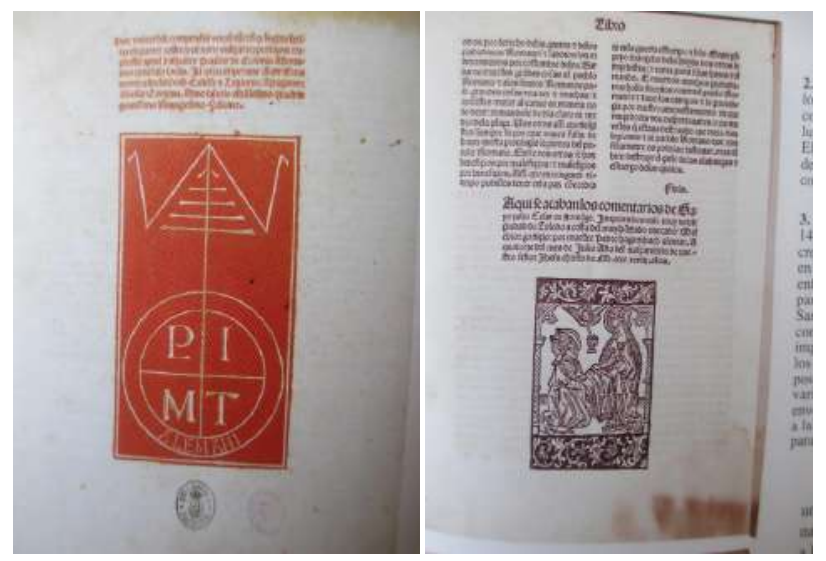

Colofón de un incunable

A su vez, Geldner en su Manual de incunables, presenta el colofón del Liber Chronicarum, conocido en español como Crónica de Nuremberg.

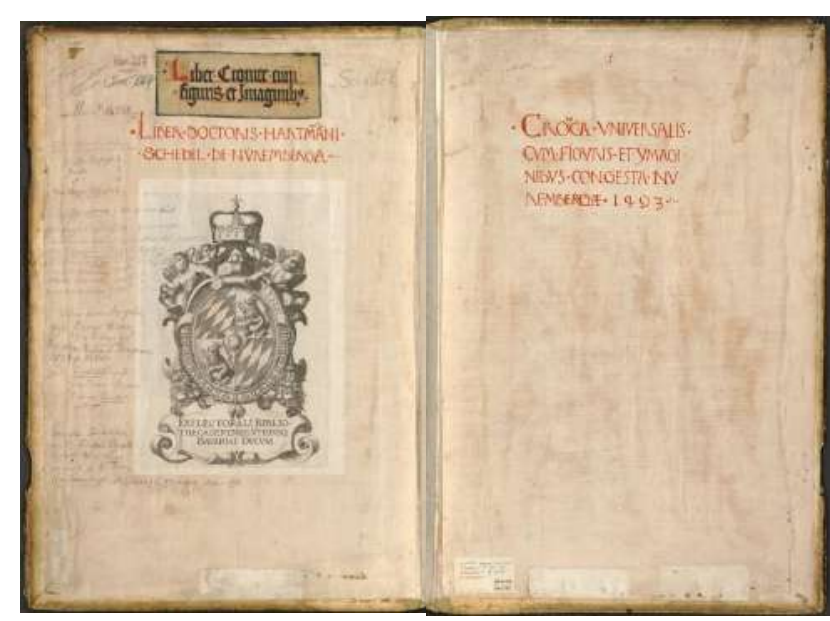

Liber Chronicarum, 1493

Al llegar los incunables, el colofón poco a poco fue perdiendo importancia porque la portada daba la información necesaria, pero muchos incunables no tenían portada, entonces el colofón proporcionaba la información sobre el autor, el impresor, el lugar y la fecha de impresión y así continuó su presencia en los siglos siguientes hasta el presente.

La información otorgada por el colofón ayudaba a identificar las obras, de allí su importancia para la historia del libro, es una manera en que los escritores decían yo lo escribí y los impresores yo lo imprimí, así daban a conocer su autoría.

El colofón en México ha tenido mucha presencia, pero recordemos primero el colofón en Europa: Geldner en su Manual de incunables asienta que el primer incunable con colofón es un libro de salmos de 1451 y menciona interesantes ejemplos del silo XV que generalmente están en latín:
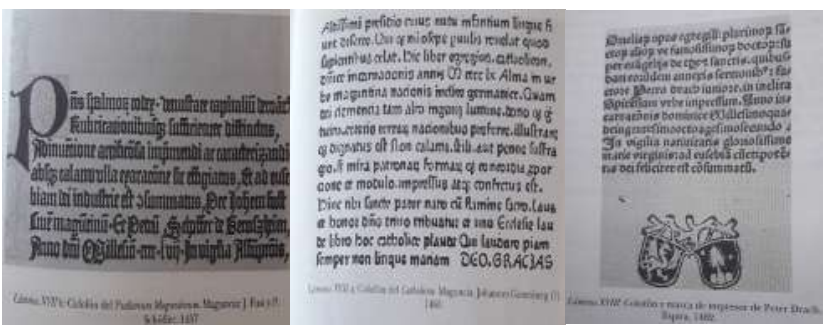

Colofones del Siglo XV. Geldner p.117-125 
El colofón llegó a México junto con la imprenta, en 1539. Por el colofón se conoce el primer libro impreso en México y en América en 1540, el Manual de adultos que se conserva en la Biblioteca Nacional de España,

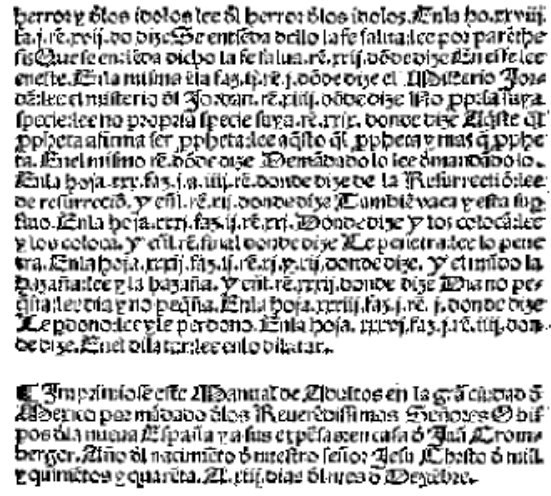

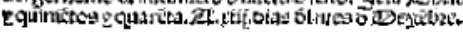

requeridos por la sociedad de aquellos tiempos, procuraron elaborarlos "bellamente". Los colofones de ese siglo no se redujeron a unos renglones, sino que aparecen con distintas formas y algunas veces acompañados de la marca del impresor o con algún adorno como se puede ver en los ejemplos siguientes.

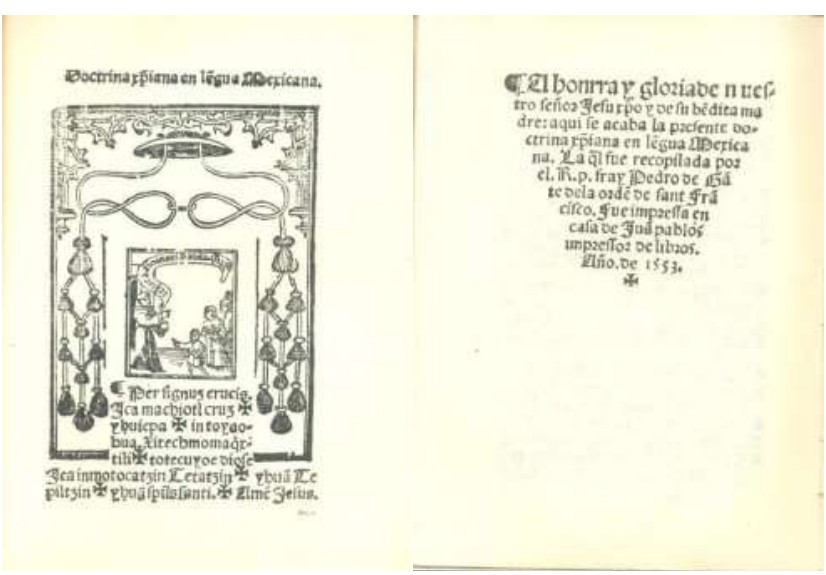

Doctrina Christiana en lengua Mexicana, Pedro de Gante Colofón de Juan Pablos, 1553

\section{Biblioteca Nacional de España \\ Manual de adultos. Colofón Juan Cromberger, 1540.}

No se conserva todo el texto, sólo unas cuantas hojas, el colofón dice:

"Imprimiose este Manual de adultos en la gran ciudad de Mexico por mandado de los Reverendísimos Señores Obispos dela Nueva España y a sus expensas en casa de Juan Cromberger. Año del nacimiento de nuestro Señor Jesu Christo de mil quinientos y quarenta. A xiii días del mes de Deziembre".

Los impresores del siglo XVI en la Nueva España, además de "hacer" los libros, folletos y hojas sueltas

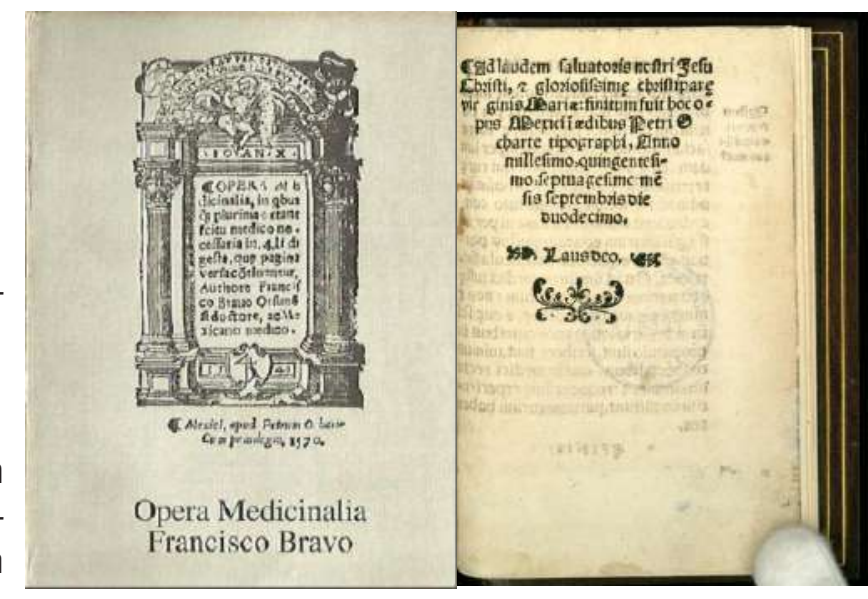

Opera Medicinalia, Francisco Bravo Colofón de Pedro Ocharte, 1570

Se puede observar que los colofones de la Doctrina Christiana y de la Opera Medicinalia, primer im- 
preso de medicina en México y en América, tiene forma triangular y la Opera una pequeña viñeta que busca dar una mayor belleza al colofón.

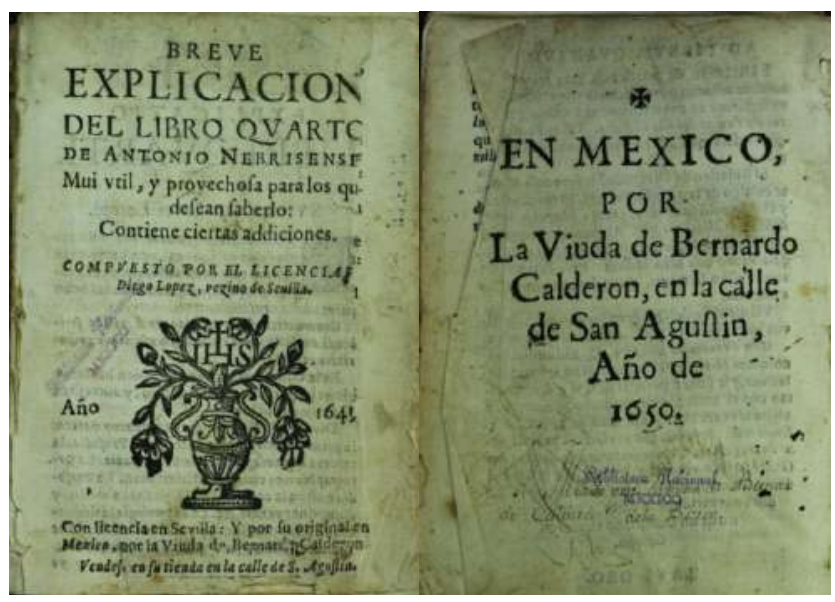

Breve Explicación del libro quarto de Antonio Nebrisensi..

Diego Lopez, 1649. Colofón de la Viuda de Bernardo Calderón, 1650

Se dan casos en que la fecha de la portada y la del colofón no coinciden.
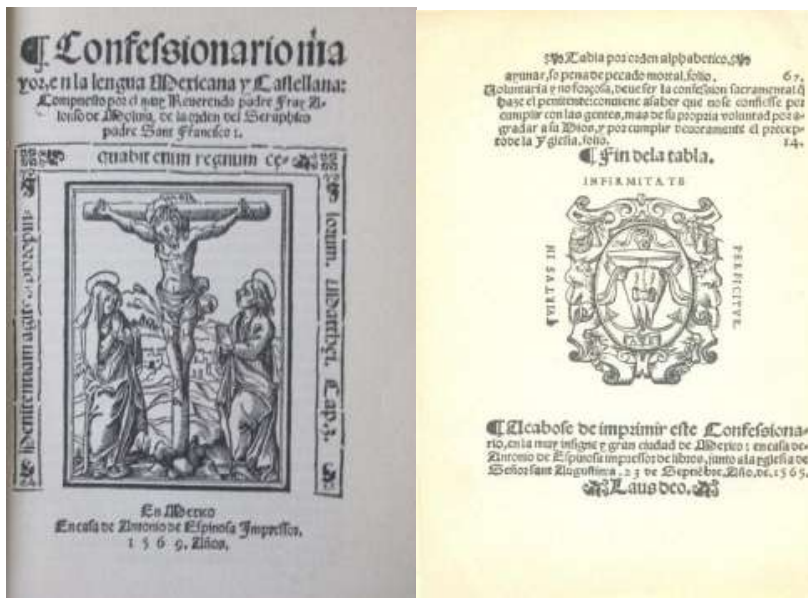

Tralabofe oe impzinir efte Eonfforolsna:

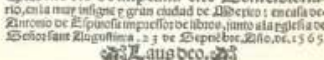

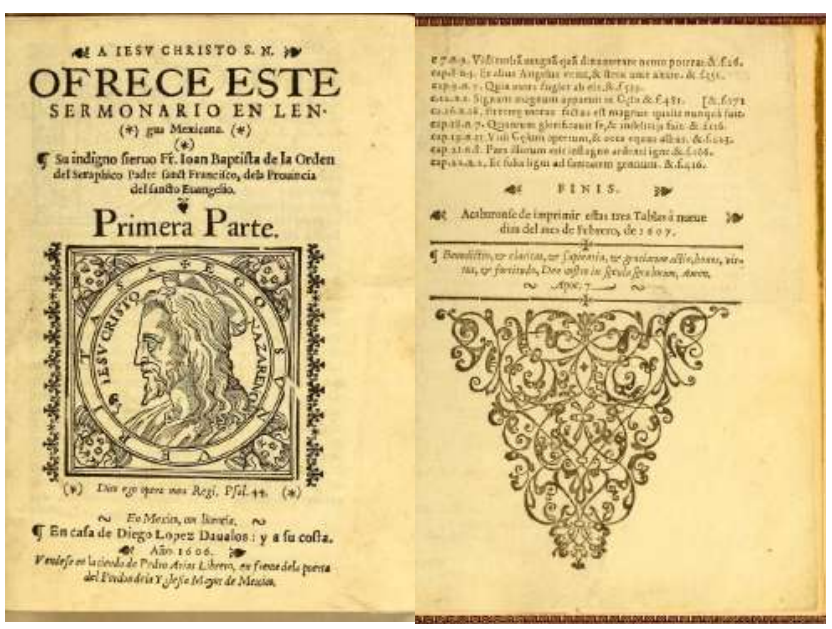

A lesv Christo S.N. Ofrece este sermonario en lengua mexicana, Juan Baptista. 1606. Colofón Diego López Dávalos 1607. BNM

La portada dice:

"En Mexico, con licencia. En casa de Diego Lopez Davalos: y a su costa. Año 1606. Vendese en la tienda de Pedro Arias Librero, en frente dela puerta del Perdon de la Yglesia Mayor de Mexico." El colofón dice: FINIS. Acabaronse de imprimir estas tres tablas á nueve días del mes de febrero, de 1607 . Termina con una hermosa viñeta.

Con estos ejemplos puede verse la importancia que tuvo la información incluida en los colofones del siglo XVI; en los siglos XVII y XVIII los colofones no están presentes en todos los impresos, poco a poco van desapareciendo porque la información necesaria se encuentra en la portada. Los impresos terminan con Fin, Laus Deo, Finis, Amen etc. y generalmente con una bella viñeta. Los colofones no proporcionaban la información que ofrecieron siglos más tarde como era el tiraje, o número de ejemplares impresos de un título, de lo que poco o nada se sabe de la época colonial.

En el Confessionario mayor, la portada dice: "En Mexico en casa de Antonio de Espinosa 1569 Años" y el colofón señala, "Acabose de imprimir este Confessionario en la muy insigne y gran ciudad de Mexico: en casa de Antonio de Espinosa impressor de libros, junto a la iglesia del señor Sant Augustine a 23 de Septiembre Año de 1565. Laus Deo". 


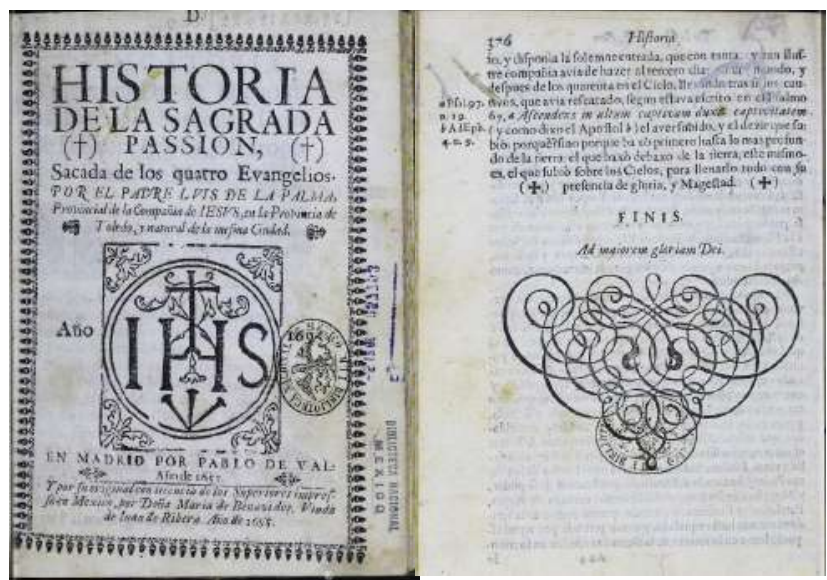

Historia de la Sagrada Passion: sacada de los quatro Evangelios. Luis de la Palma. Impreso por Doña María de Benavides, Viuda de Juan de Ribera, 1695. FINIS Sin colofón.
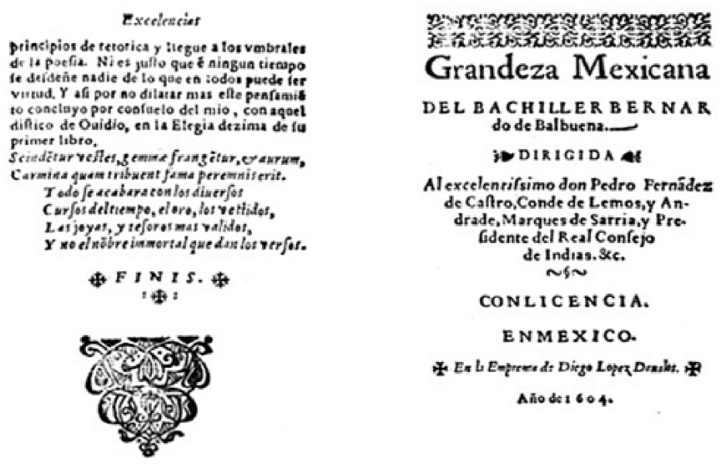

Grandeza Mexicana. Bernardo de Balbuena. Diego López Dávalos, 1604. Sin colofón

En el siglo XVIII pocos libros llevan colofón. En dicho siglo trabajaron cerca de 40 impresores, Elsa Cortés menciona que en este siglo solo se tiene el conteo de 31 impresores registrados muchos de ellos descendientes de las familias impresoras del siglo anterior; destacan los Herederos de la viuda de Francisco Rodríguez Lupercio, Herederos de Guillena Carrascosa, Herederos de María de Ribera, Herederos de la viuda de Miguel de Ribera Calderón. Aparecen personajes nuevos como José Bernardo de Hogal quien moderniza la tipografía novohispana, también destacó su viuda. Felipe de Zúñiga y Ontiveros, sin duda uno de los mejores impresores de este siglo, fue además un notable matemático, astrónomo y agrimensor. (Torre Villar p. 155) Publicó la Guia de Forasteros y los Estatutos de la Real Academia de San Carlos. En este siglo aparece la primera imprenta institucional, la del Colegio de San Ildefonso, de los jesuitas, y una especial, la Imprenta de la Biblioteca Mexicana (1753-1757) adquirida por don Juan José Eguiara y Eguren para imprimir su famosa Bibliotheca Mexicana, primera bibliografía impresa en América.

\section{Ejemplo del siglo XVIII}

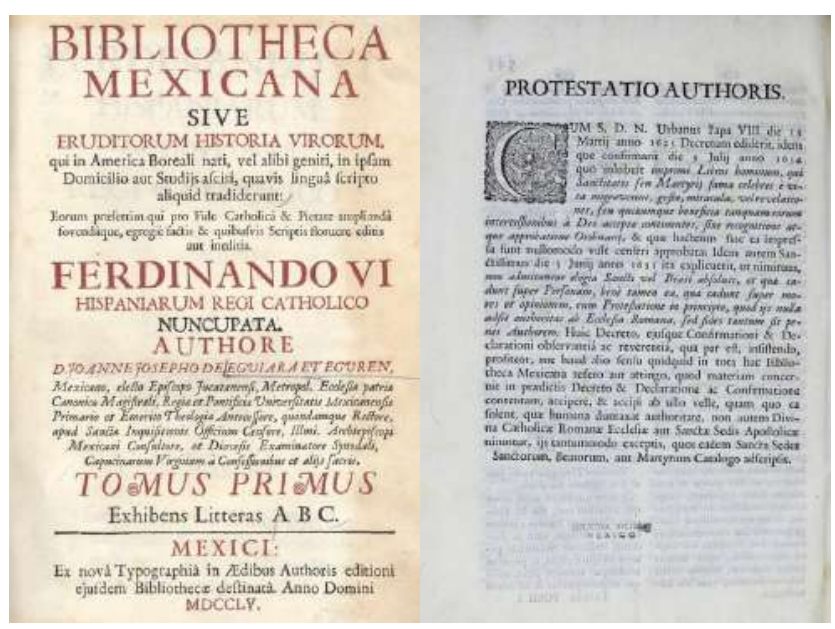

Bibliotheca Mexicana sive Eduritorum Virorum. México, 1755

En el siglo XIX, ya en el México independiente y hasta finales del siglo, el colofón aparece sólo en algunos títulos y ocasionalmente junto a noticias curiosas como puede verse en el siguiente texto de la ciudad de México. Fue el siglo de grandes cambios, aparece la litografía, hay avances tecnológicos significativos que ayudan a la industria editorial, es el siglo de los periódicos, revistas, guías de forasteros, calendarios, etcétera. 


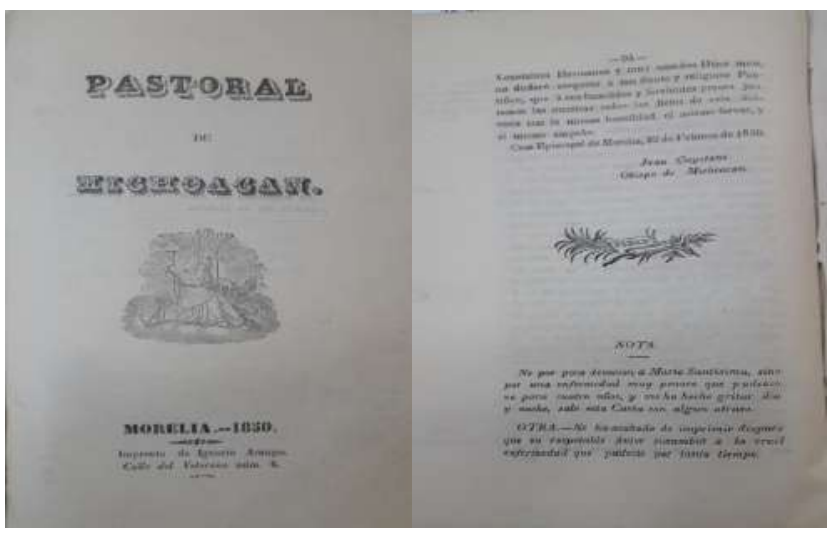

Pastoral de Michoacán. 1830

La Nota dice:

\section{NOTA.}

No por poca devocion a Maria Santisima, sino por una enfermedad muy penosa que padezco va para cuatro años, $y$ me ha hecho gritar dia y noche, sale esta Carta con algun atraso.

OTRA. - Se ha acabado de imprimir despues que su respetable Autor sucumbio a la cruel enfermedad que padecio por tanto liempo.

La primera edición del Quijote impresa en México tampoco tiene colofón:

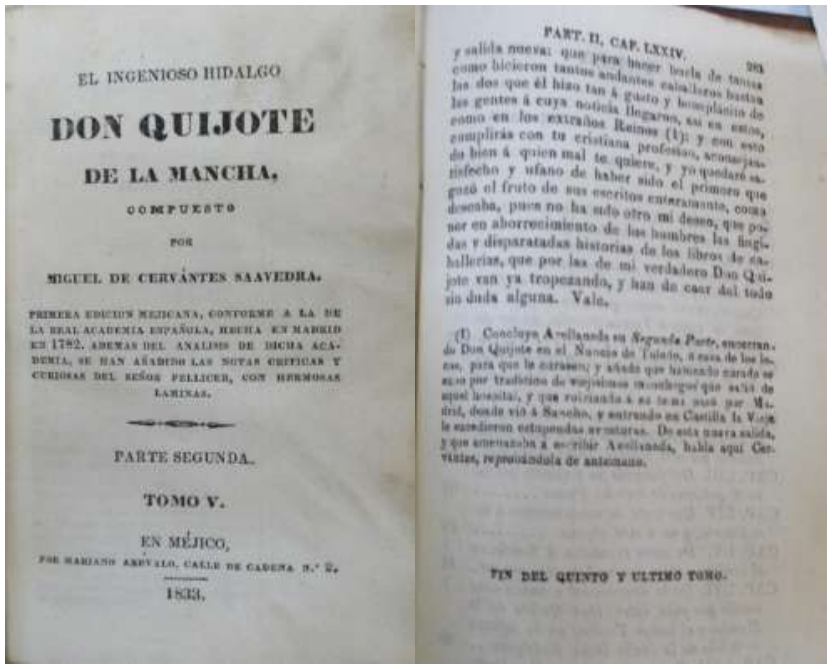

El ingenioso hidalgo Don Quijote de la Mancha. M. de Cervantes Saavedra Primera edición en México, 1833. 5 vols. Sin colofón

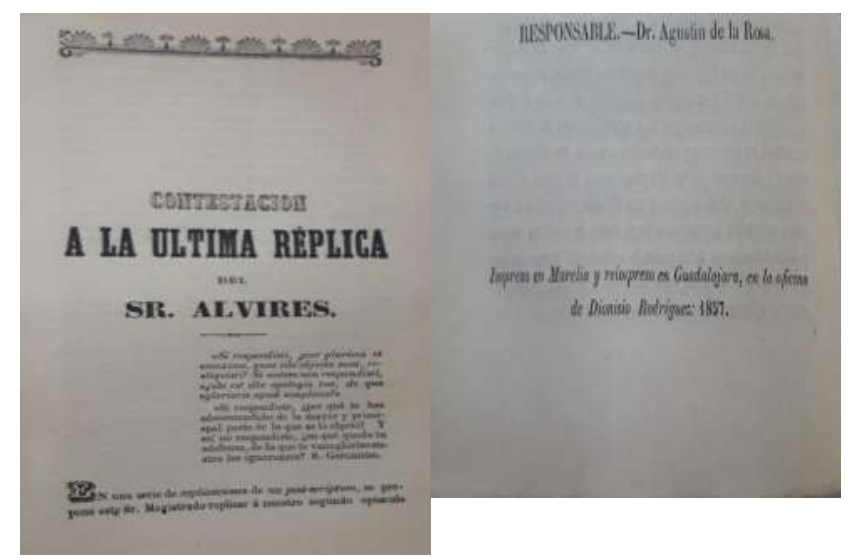

Contestación a la última réplica del Sr. Alvires Morelia y Guadalajara. Colofón de Dionisio Rodríguez 1857

Hacia fines del siglo XX, pero especialmente en el siglo XXI, aparecen algunos colofones en forma de caligrama que son una verdadera aportación artística a la tipografía mexicana, como se podrá ver más adelante.

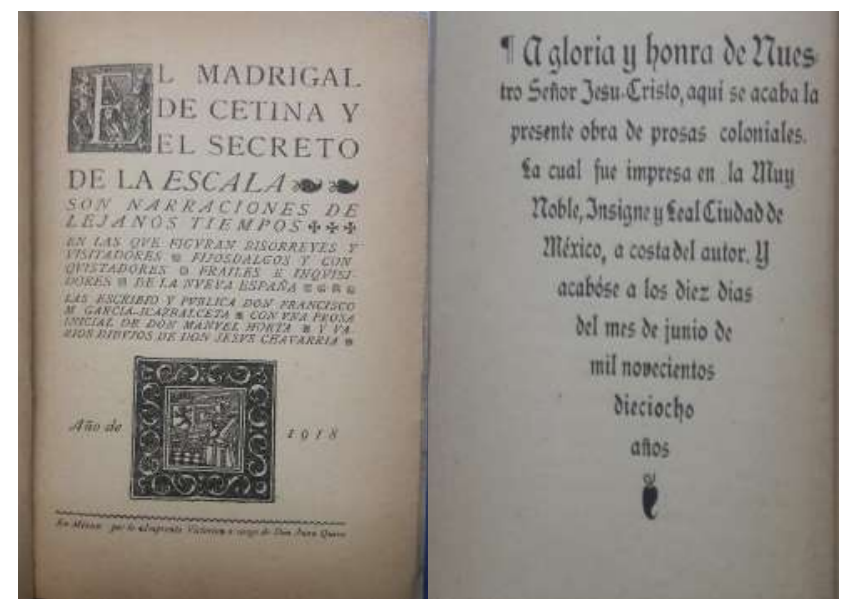

El Madrigal de Cetina y El secreto de la escala....F. M. García Icazbalceta Imprenta Victoria. 1918 Colofón

Hemos visto la evolución de este elemento, también la presencia de la mujer en los impresos y la belleza de los colofones en la época de la colonia, pero veamos como resurge con fuerza en el siglo XX hasta el presente, esto se da entre otras razones por las disposiciones legales que en 1917 obligaban a mencionar en todo impreso 
el nombre del autor, del impresor y dónde se encontraba, no querían que se hicieran críticas al gobierno y de hacerlo podrían encontrar fácilmente al culpable y castigarlo.

Sin embargo, hay que recordar que ya en el silo XIX se había dado una apertura a la libertad de imprimir con la Constitución de Cádiz en 1812, que se respeta también en la Nueva España, por lo que hay también libertad de información, así que se vive una libertad que los impresores aprovechan de muchas maneras.

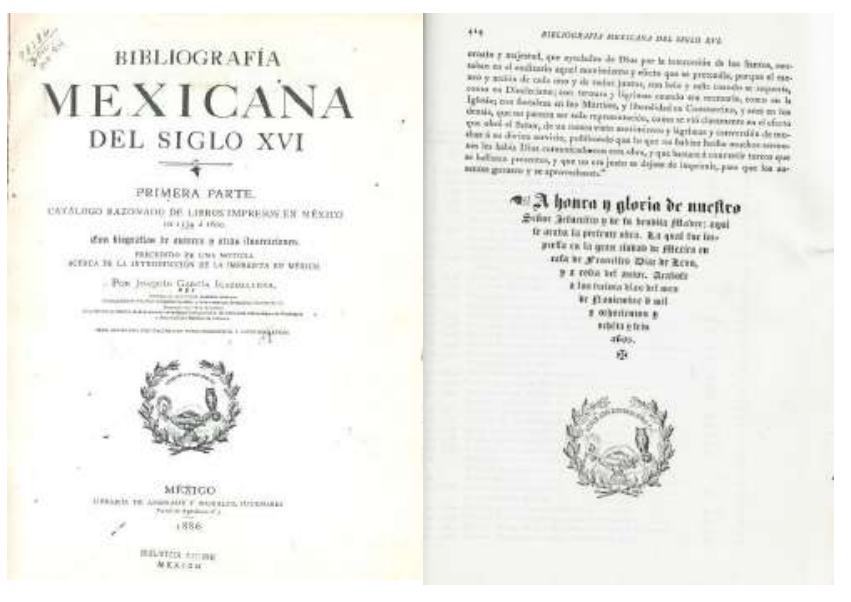

Bibliografía Mexicana del siglo XVI.1886 Colofón y marca de J. García Icazbalceta

En el siglo XX no había estas limitaciones legales y la presencia de los colofones es muy basta por lo que pregunté al presidente de la CANIEM (Cámara Nacional de la Industria Editorial de México) el porqué de esta presencia y sobre todo del tiraje que creo es una tradición muy mexicana porque en los países europeos generalmente no se menciona, tal vez en España y en algunos países latinoamericanos de vez en cuando se utilice, pero no es lo usual, contestó que era por un acuerdo entre autores y editores porque a mayor número de ejemplares impresos, mayor popularidad y mayores regalías para el autor que se sentía muy alagado con el tiraje de mil ejemplares o más. Pero por ley nunca se ha pedido el tiraje.
Por otra parte, el colofón como manifestación artística, como elemento iconográfico tiene un impacto visual en el libro, como ya se mencionó.

Daniel de Lira Luna en su obra titulada: La producción editorial de Gabriel Fernández Ledesma, Francisco Díaz de león, Miguel N. Lira y Josefina Velázquez de León. Su organización bibliográfica y su valor patrimonial (2013), es el estudio más valioso que se ha realizado de una parte de la primera mitad del Siglo $X X$, cita los editores que se establecen en el siglo XX. Numerosas son las editoriales públicas y privadas que surgen desde la primera mitad del siglo veinte, como la Editorial Cultura, la Librería Herrero, Porrúa Hermanos, Botas, la Dirección General de Publicaciones de la Secretaría de Educación Pública a partir de 1921, el Departamento de Prensa y Publicidad de la Secretaría de Relaciones Exteriores en 1923, los Talleres Gráficos de la Nación, la Editorial Patria, y muchas otras editoriales independientes. Otra imprenta destacada fue la Imprenta del Museo Nacional, su primer impreso fue dedicado al presidente Porfirio Díaz, el cual lleva por título: Porfirio Díaz sus padres, niñez y juventud, 1906. En su bello colofón menciona: "Aquí hace fin el presente libro, que fue impreso a la honra del señor Presidente general Porfirio Díaz en la muy noble, leal e insigne ciudad de México por Luis G. Corona, regente de la imprenta del Museo Nacional, a fines del mes de diciembre del 1906."

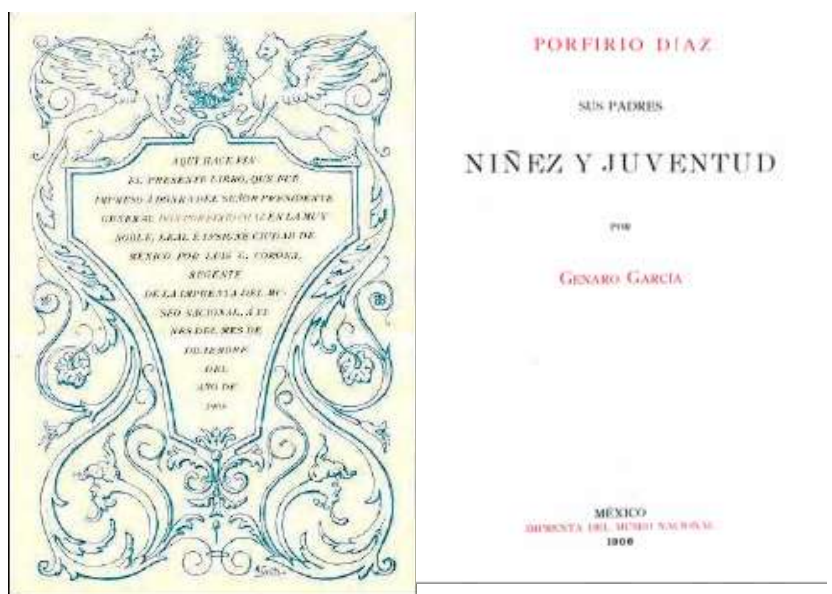

Porfirio Díaz: sus padres, niñez y juventud. Genaro García Colofón. Imprenta del Museo Nacional, 1906 
Ejemplos de colofones del siglo XX:

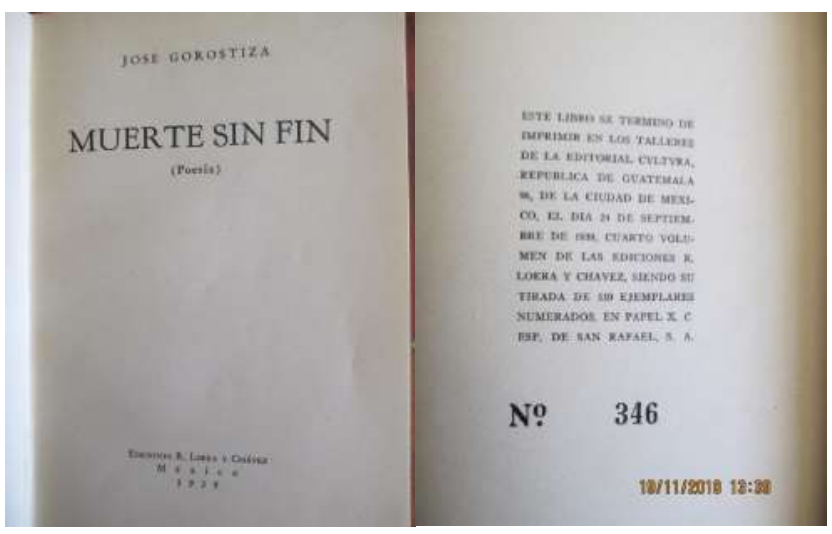

Muerte sin Fin. José Gorostiza Colofón, 1939

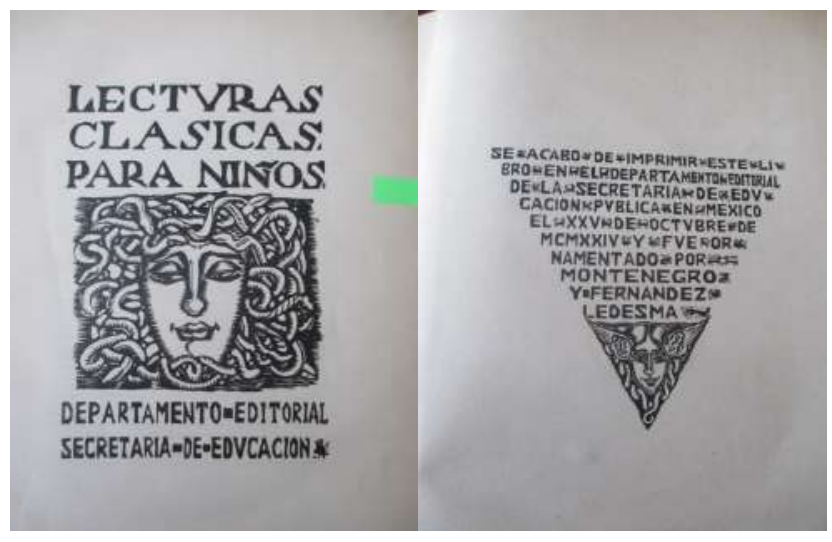

Lecturas clásicas para niños 1924 vol.1 Portada y colofón

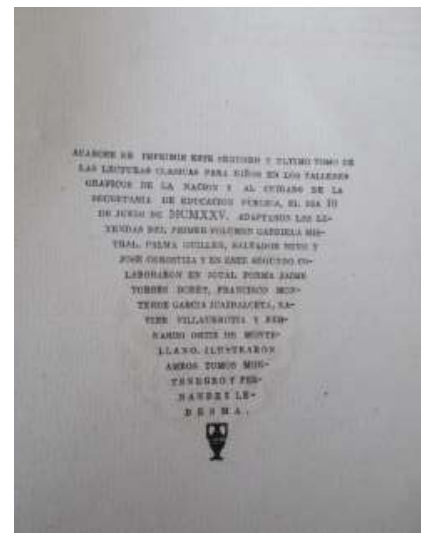

Lecturas clásicas para niños SEP, 1925 vol.2 Colofón
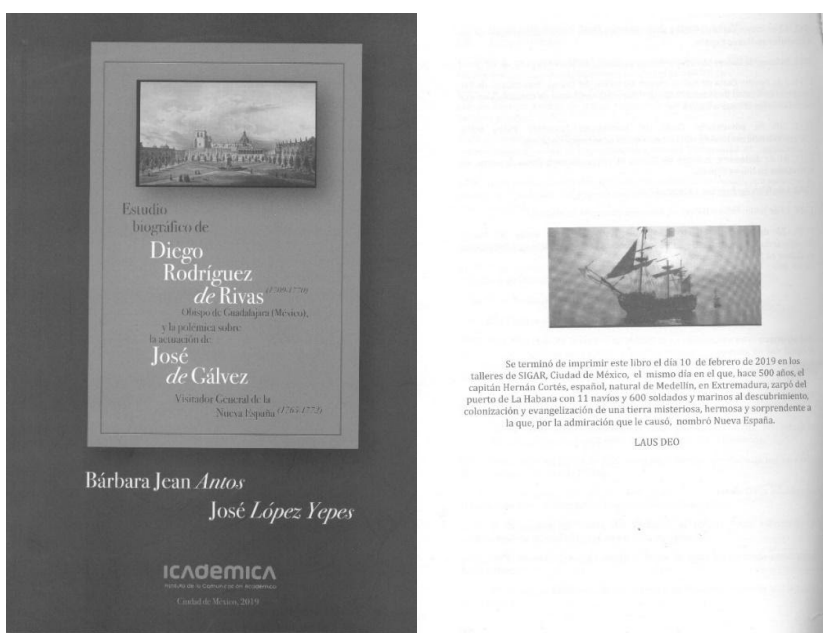

Estudio biográfico de Diego Rodríguez de Rivas. 2019. Colofón sin número de ejemplares.

El colofón dice: "Se terminó de imprimir este libro el día 10 de febrero de 2019 en los talleres SIGAR, Ciudad de México, el mismo día en el que hace 500 años, el capitán Hernán Cortés, español natural de Medellín, en Extremadura, zarpó del puerto de La Habana con 11 navíos y 600 soldados y marinos al descubrimiento, colonización y evangelización de una tierra misteriosa, hermosa y sorprendente a la que, por la admiración que le causó, le nombró Nueva España. LAUS DEO

En la obra titulada Escenarios gastronómicos de Clementina Díaz y de Ovando, editado por la UNAM, se encuentra un interesante colofón impreso el 27 de diciembre de 2011.

El colofón informa sobre la parte material del
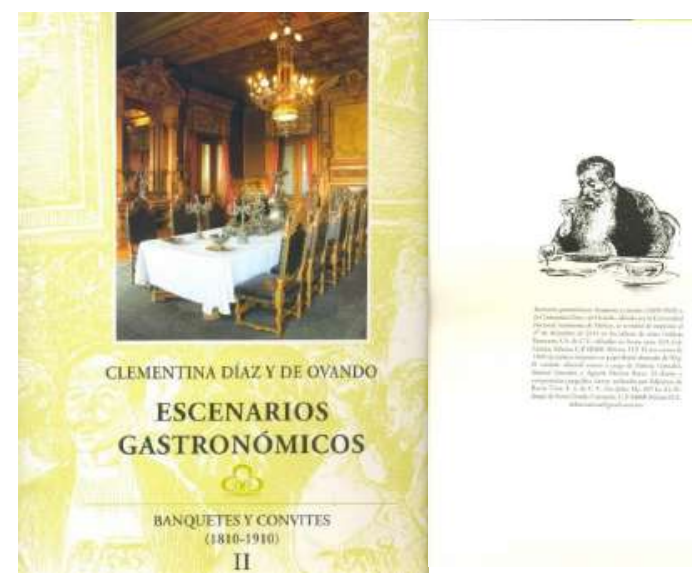
libro. El tiraje es muy variado, va desde un ejemplar hasta millones de ejemplares. El colofón se queda con el editor y deja de ser el elemento que daba noticia de la publicación y pasa a ser elemento de adorno y homenaje porque actualmente se pone como fecha de terminación alguna fecha importante para el editor, como el día de su santo o cumpleaños.

Sin embargo, en México siguen apareciendo colofones con toda la información requerida ya mencionada y en formas muy artísticas.

Así pues, el colofón da cuenta del tiraje de las obras impresas. De esta manera encontramos desde la impresión de un sólo ejemplar que es el caso de la edición de la Suite única de las maderas del libro de Oaxaca de M. Toussaint, del año 1926 que se encuentra en la Biblioteca Cervantina del Instituto Tecnológico de Estudios Superiores de Monterrey (ITESM), hasta llegar a 27.5 millones de ejemplares de la edición del Periquillo Sarniento del año 2006 realizada por la Comisión Nacional de los Libros de Texto.
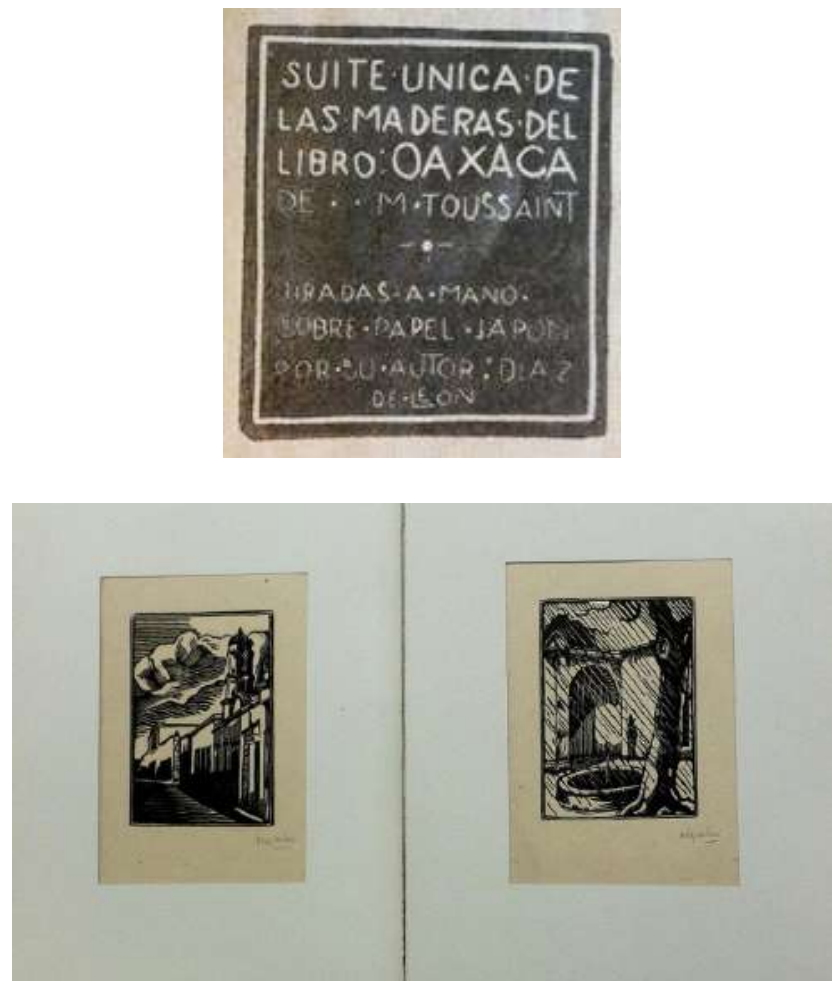

Suite única de las maderas del libro Oaxaca de M. Toussaint. Francisco Díaz de León, 1926. Un ejemplar.

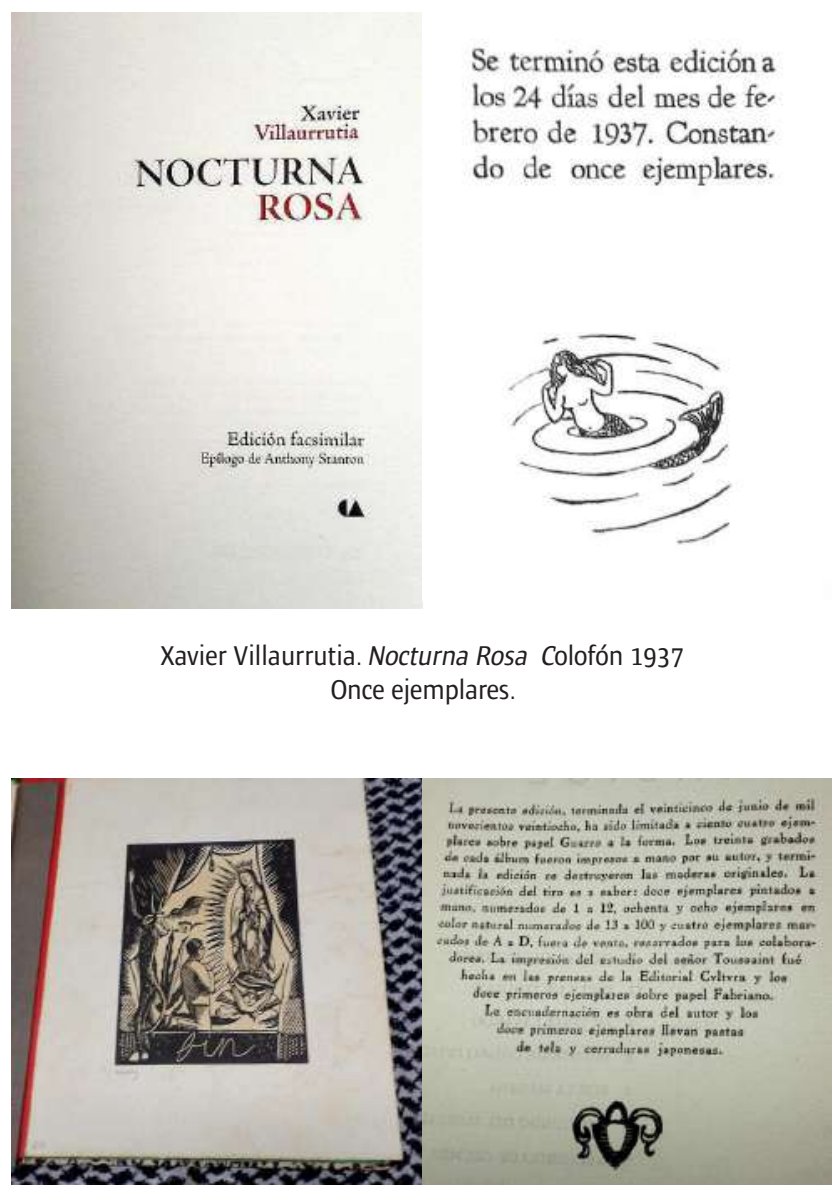

Treinta asuntos mexicanos grabados en madera. F. Díaz de León. 1928. Con estudio de M. Toussaint. Tiraje 104 ejemplares que se explican en el colofón.

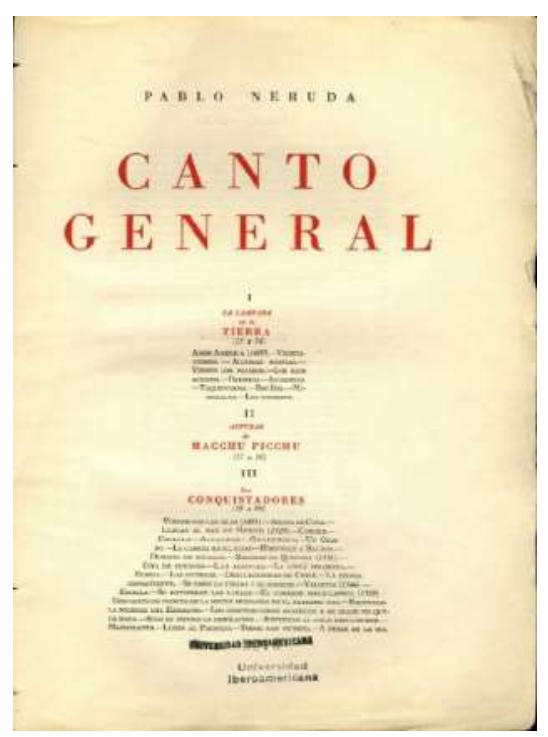




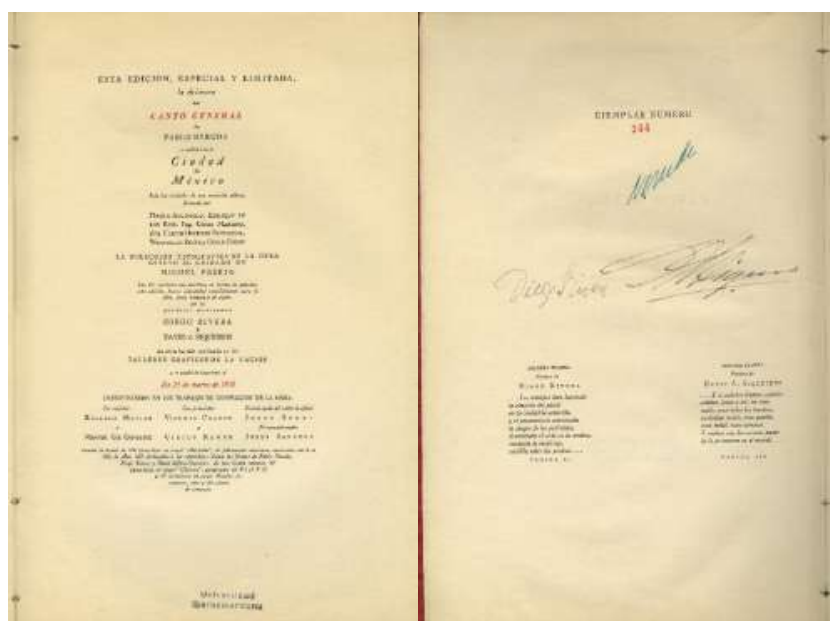

Canto General. Pablo Neruda, 1950. Tiraje de 500 ejemplares, más 50. De ellos 300 ejemplares firmados para los suscriptores por el autor y los pintores

Destaca este colofón en forma de pera:

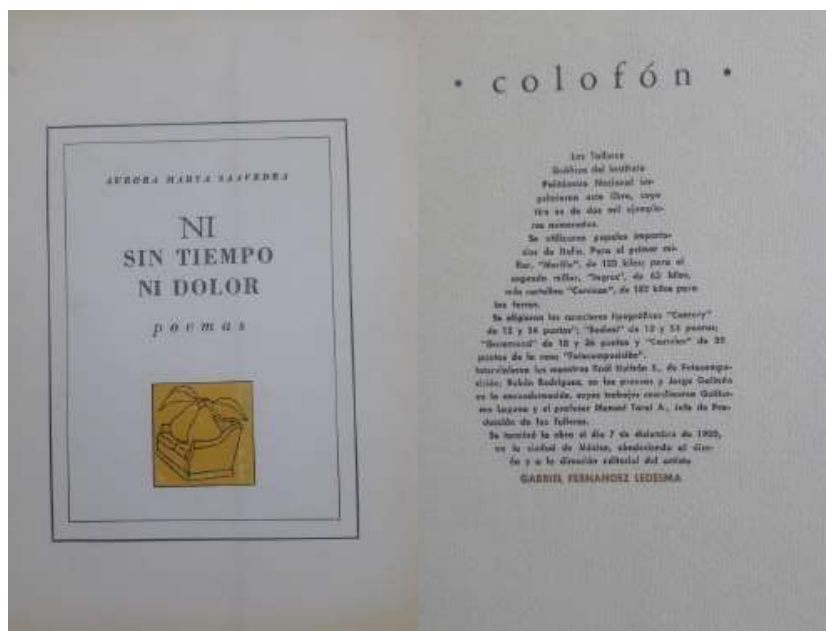

Ni sin tiempo ni dolor: poemas Aurora Marya Saavedra, 1950 Dos mil ejemplares

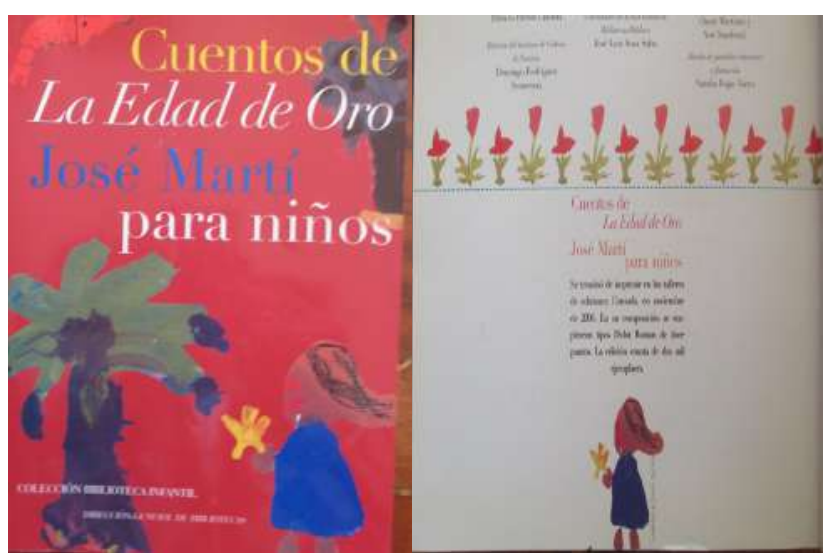

Cuentos de La Edad de Oro José Martí para niños

Ediciones Corunda. Colofón, dos mil ejemplares
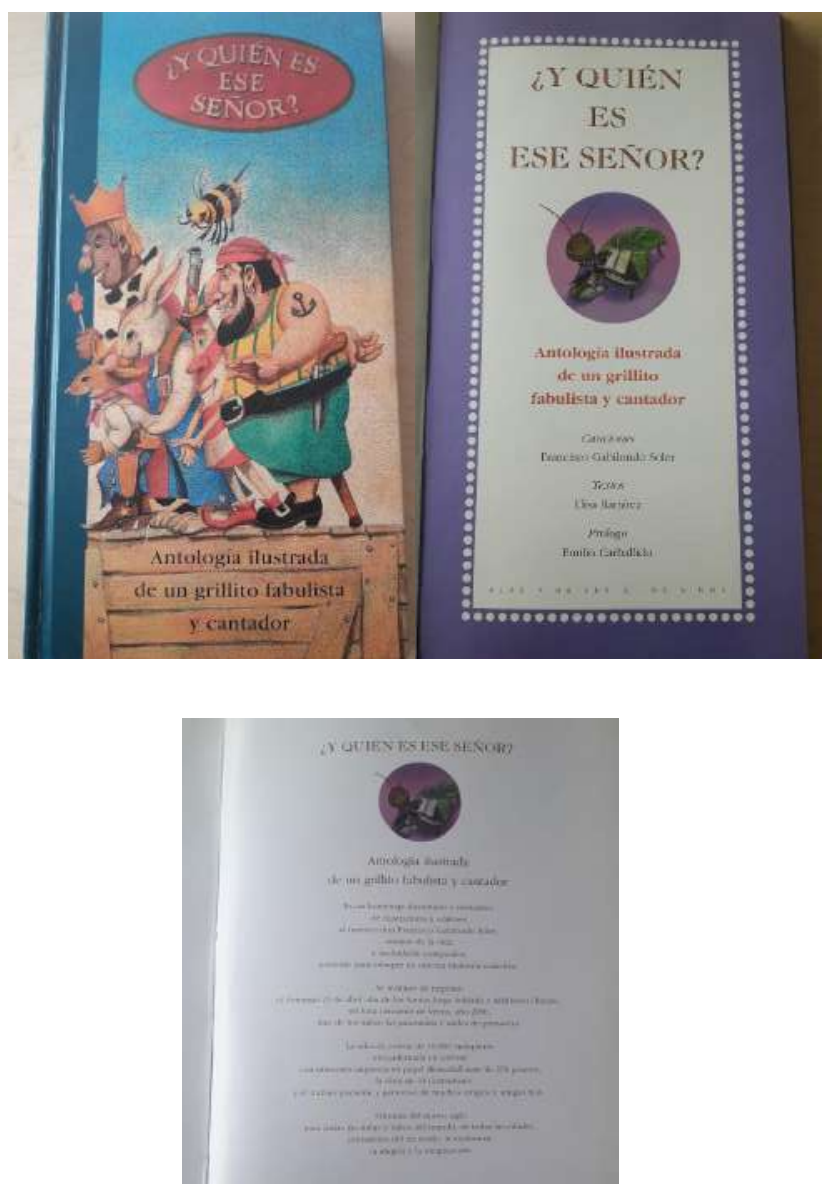

¿Y quién es ese señor? Cri-Cri. Editado en el año 2000 Colofón, 10,000 ejemplares

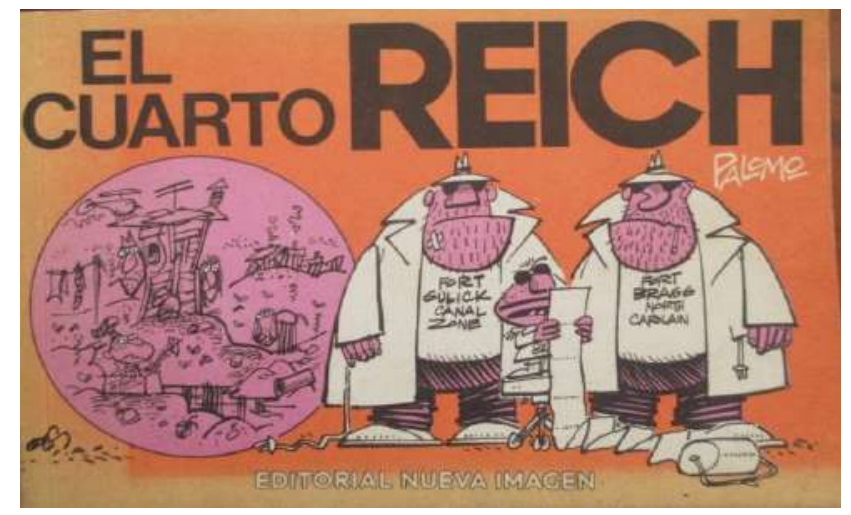




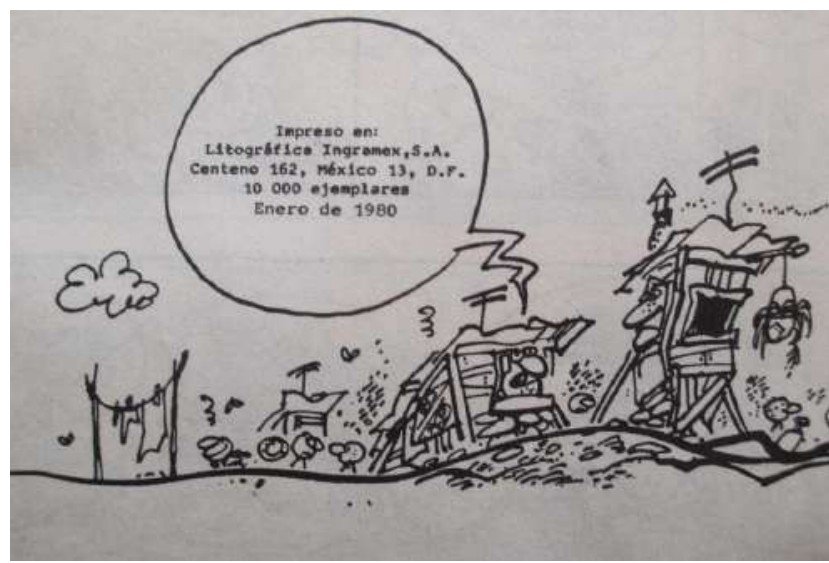

El cuarto Reich. Palomo 1980, Colofón 10, 000 ejemplares

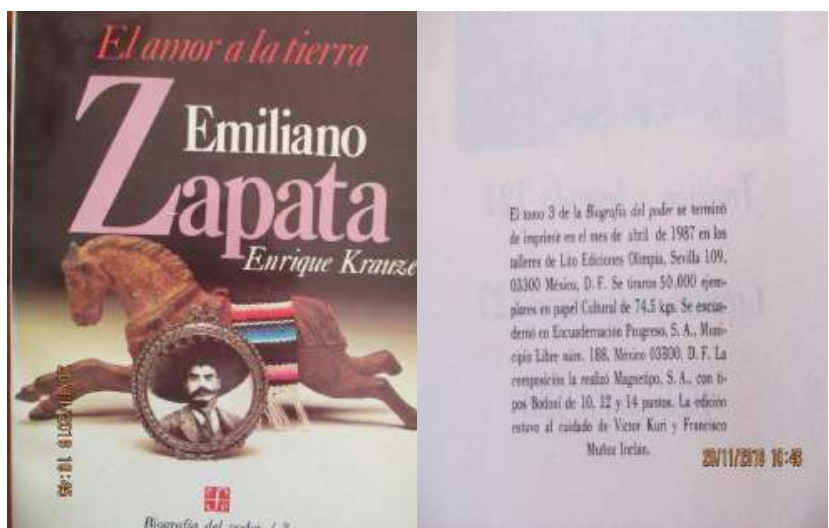

El amor a la tierra. Emiliano Zapata. Enrique Krauze. 1987 Colofón 50,000 ejemplares.

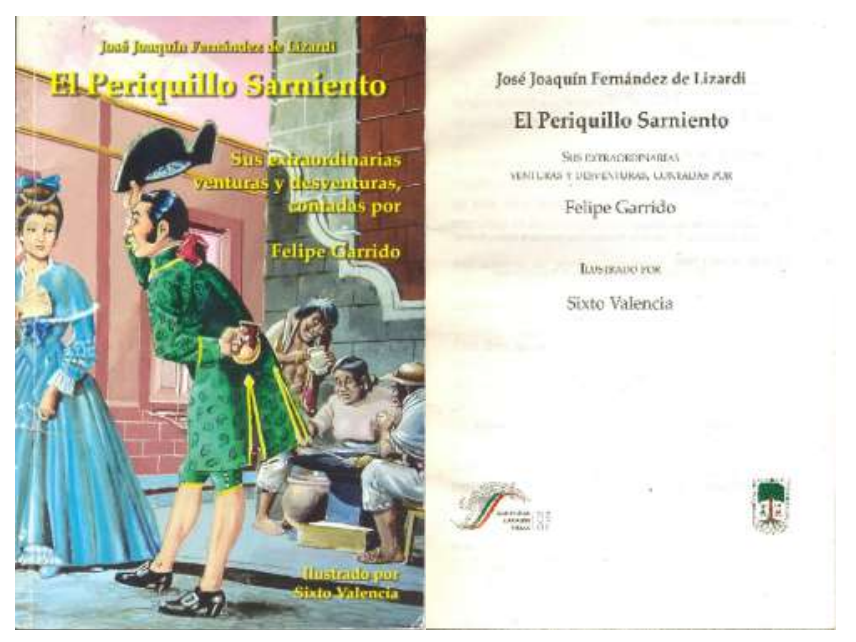

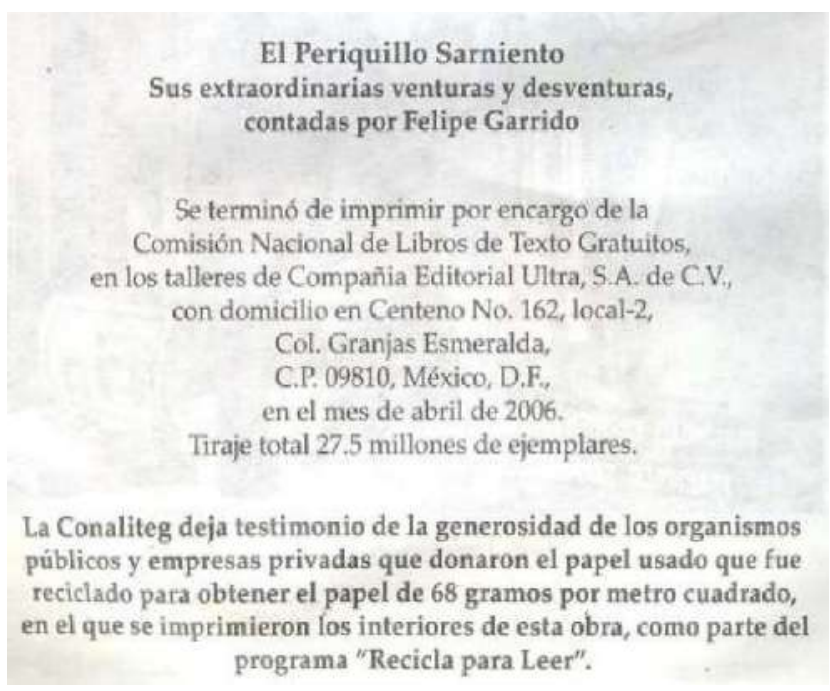

El Periquillo Sarniento J.J. Fernández de Lizardi, versión de Felipe Garrido, 2006 Colofón 27.5 millones de ejemplares.

Curiosamente este libro no se encuentra en la Biblioteca Nacional ni se localiza en LIBRUNAM.

El colofón no solo ha cumplido con ofrecer la información sobre el autor, la imprenta o el impresor involucrados, sino que desde el siglo XVI los impresores han puesto todo de su parte para que esta información aparezca en muchos casos lo más atractiva y bella posible.

Konrad Haebler dice que los primeros impresores de Roma y Venecia introdujeron la costumbre de dar al colofón una forma métrica y varias veces en forma geométrica, en forma de triángulo. Los versos se repetían casi sin cambios en los diversos libros y numerosos editores utilizaron los colofones métricos, son famosos los de La Celestina y este que menciona José Simón Díaz (p. 216) como ejemplo, que se encuentra en Loas de Maral Dantisco: en prosa a las famosas y muy excelentes coplas de don Jorge Manrique por Luis de Aranda: 
A su costa del auctor

Por el mesmo corregida

Por la officina salida

De Cordoua el impresor

En seguida, se dan ejemplos de bellos colofones/caligramas:

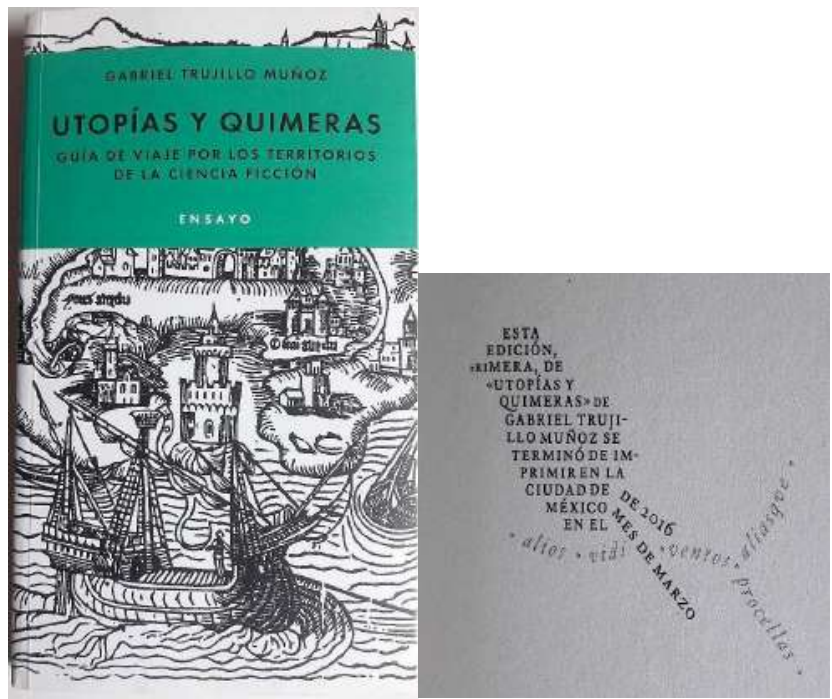

Utopías y quimeras. Gabriel Trujillo Muñoz. 2016 Colofón/Pájaro

El libro publicado por la editorial MR con motivo de los 60 años de Pedro Páramo, tiene un original y bello colofón que dice: "Pedro Páramo 60 años se terminó de imprimir en julio de 2015 en Artes Gráficas Panorama, ciudad de México. En su formación se utilizaron las fuente Dolphian y Warnock Pro. Se tiraron mil ejemplares. México MMXV".
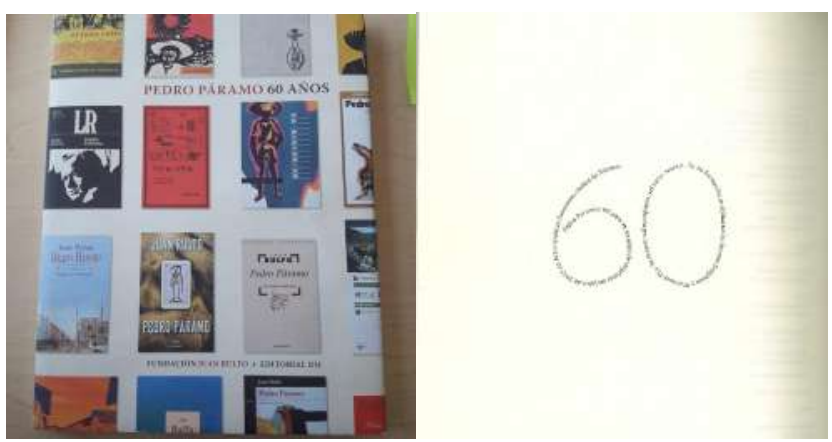

Pedro Páramo 60 Años. Editorial RM 2015

Colofón 1000 ejemplares
Si bien el siguiente libro no fue impreso en México sino en Valencia, trata de México, la editorial RM tiene sede en la ciudad de México y el colofón no puede ser más mexicano.

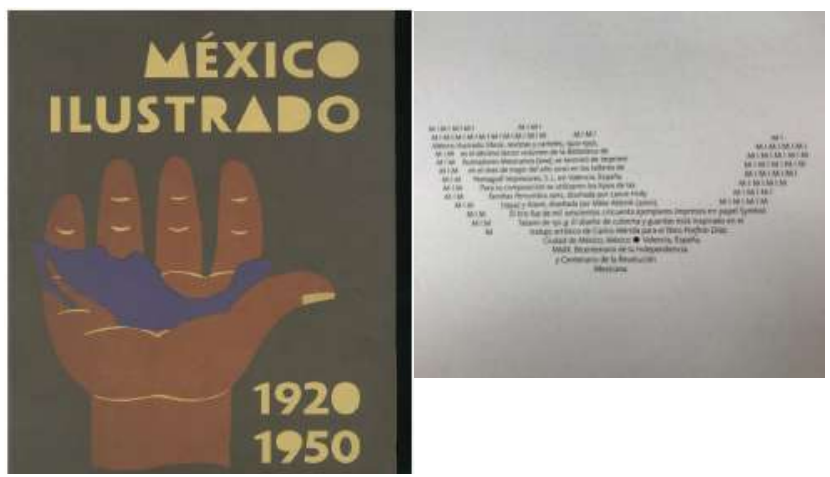

México ilustrado. 1920-1950. Editorial RM 2017 Colofón 1650 ejemplares

El colofón dice: "México ilustrado, libros, revistas y carteles, 1920-1950. Es el décimo tercer volumen de la Biblioteca de Ilustradores Mexicanos (BIM), se terminó de imprimir en el mes de mayo del año 2010 en los talleres de Pentagraf Impresores, S.L en Valencia, España. Para su composición se utilizaron los tipos de las familias Penumbra sans, diseñada por Mike Abbink (2001). El tiro fue mil seiscientos cincuenta ejemplares impresos en papel Symbol Tatami de 150 g. El diseño de cubierta y guardas está inspirado en el trabajo artístico de Carlos Mérida (para el libro Porfirio Díaz. Ciudad de México, México. Valencia, España. MMX Bicentenario de la Independencia y Centenario de la Revolución Mexicana”.

Con estos bellos colofones termino este artículo sobre los colofones en el libro en México siglos XVI a XXI. I 


\section{LIBROS Y LECTURA}

\section{REFERENCIAS}

» De los incunables al siglo XVIII: historia ilustrada del libro español/bajo la dirección de Hipólito Escolar (1998), Madrid, Fundación Germán Sánchez Ruipérez/Pirámide, 1998.

»Escolar Sobrino, Hipólito (1993). Historia universal del libro. Madrid, Piramide.

» Fernández de Zamora, Rosa María (2009). "Sobre los colofones", en Los impresos mexicanos del siglo XVI..., 309-313. México, UNAM.CUIB

» Fevbre, Lucien y Henri Jean Martin (2000). La aparición del libro. Guadalajara, Ediciones Castor/U. de Guadalajara.

» Geldner, Ferdinand (1998). Manual de incunables: introducción al mundo de la imprenta primitiva. Madrid, Arco Libros.

» Haebler, Konrad (1995). Introducción al estudio de los incunables. Edición,

» prólogo y notas Julián Martín Abad. Madrid, Ollero \& Ramos, 1995.

» Historia ilustrada del libro español. De los incunables al siglo xviii (1994). Bajo la dirección de Hipólito Escolar. Madrid, Fundación Germán Sánchez Ruipérez.

» Hernández Moreno, Antonio y Manuel Ayuso García (2015) "Los paratextos de las ediciones humanísticas de obras latinas en la antigüedad: el tratamiento de la portada, el prefacio y el colofón en las ediciones de Marciano Capela (ss xv y xvi)", Ágora. Estudios Clásicos en Debate, 17 de enero, p. 65-132.

» Iguíniz, Juan B. (2014) El libro. Epítome de bibliología. México, Porrúa, 2014.

» Iguínez, Juan B. (1987). Léxico bibliográfico. México, UNAM.Instituto de Investigaciones Bibliográficas.

» Marsá, María (2001). La imprenta en los Siglos de Oro. Madrid, Ediciones del Laberinto.

» Mata, Oscar (2002).'Los Presentes, del maestro editor Juan José Arreola”, en Literatura Mexicana, v. 13 no. 2, 2002 p. 187-201. COMPROBAR

» México ilustrado. Libros, revistas y carteles 1920-1950 (2010). Edición al cuidado de Salvador Albiñana. Valencia, Editorial RM.

» Pacheco, José Emilio (2017). Inventario: Antología. Selección de Héctor Manjarrez y otros. México, Era, El Colegio Nacional, UNAM.

» Reyes Gómez, Fermín de los (2000). El libro en España y América. Legislación y censura (siglos Xv-xviii). Madrid, Arco Libros, 2 v.

» Simón Díaz, José (2000). El libro español antiguo. Madrid, Ollero y Ramos.

» Smith, Margaret M. (2000)IThe title-page its early development 1460-1510. Londres, The British Library \& Oak Knoll Press.

» Tello Díaz, Carlos (2018). Porfirio Díaz. Su vida y su tiempo: La ambición 1867-1884. México, Penguin Random House. Grupo Editorial.

» Torre Villar, Ernesto de la (1999). Breve historia del libro en MéxiCo, 3 ed. México, UNAM, 1999. 